\title{
How Do Quantitative And Qualitative Factors Influence The Selection Of Comparable, Competitive, And Aspirant Groups Under The Proposed AACSB Accreditation Maintenance Process?
}

Edd R. Joyner, (E-mail: ejoyner@utm.edu), The University of Tennessee at Martin Ernest R. Moser, (E-mail: emoser@utm.edu), The University of Tennessee at Martin Richard B. Griffin, (E-mail: rgriffin@utm.edu), The University of Tennessee at Martin

\begin{abstract}
The AACSB Blue Ribbon Committee on Accreditation Quality was "formed to do a thorough review of AACSB International's accreditation standards and procedures and to propose changes appropriate for global quality leadership in the next decade..." Within the proposal from the Blue Ribbon Committee is a change from a reaffirmation process with a site visit every ten years to a maintenance program resulting in a team visit in the sixth year of the cycle. Under the old standards applicants were required to submit "to the appropriate accreditation committee chair, in care of the AACSB International office, five nominations for each team role; i.e., five names for chair, five names for advisor, five for member, and if accounting accreditation were applicable, five names for vice-chair and five names for accounting advisor." The proposed standards include a team selection process whereby the "applicant submits three comparison groups selected from members of the Accreditation Council... AACSB International will develop an on-line system to assist the applicant to identify potential comparison schools, officially select schools for each comparison group, and continuously maintain comparison group listings in an AACSB International database. Some information is currently available. The on-line service, www.aacsb.edu/knowledgeservices, offers advanced search functions that produce institution lists based on optionally selected criteria." This AACSB provided information as well as information from other sources constitutes the basis for the recommended comparison group selection process.

This paper provides an overview of publicly available information that, while flawed, should provide a reasonable basis for determining group assignments. Examination of both quantitative and qualitative factors should be considered when making nominations for comparable, competitive, and aspirant group memberships. While quantitative information can be obtained from AACSB, other information sources must be considered. In addition to considering qualitative information, the quality of quantitative information must also be evaluated. This paper concludes by noting several weaknesses in the AACSB database as well a few warnings concerning the validity of AACSB's on-line database and other data sources.
\end{abstract}

\subsection{Decision Framework}

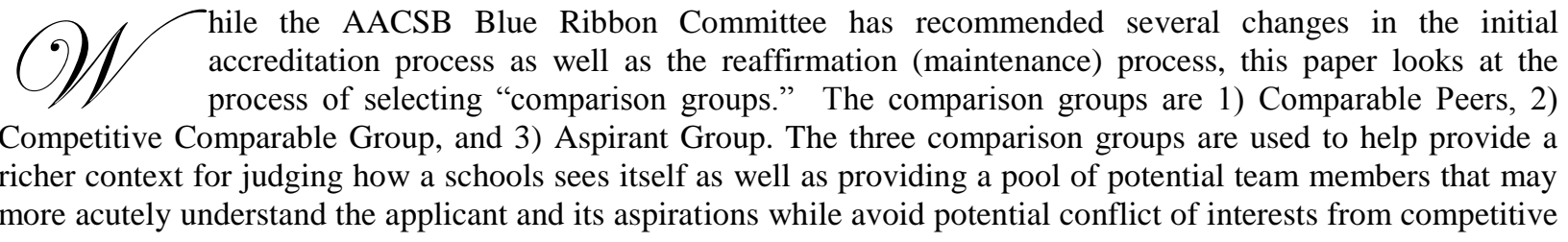


schools.

Comparable Peers: A list of schools considered similar in mission and assumed appropriate for performance comparison. A minimum of six comparable schools must be provided. The schools should be chosen carefully to match key characteristics of the applicant. In addition to mission, some features that might be salient when choosing comparison schools include student populations served, size, degree levels, and primary funding source.

Competitive Comparable Group: A list of schools so directly competitive that conflict of interest considerations exclude their personnel from the review process. The competitive school list may be of any number. Only those schools should be included where the direct competition for students, faculty, or resources is so compelling that the appearance of a conflict of interest is present.

Aspirant Group: A list of schools that provides a developmental goal for the applicant, represents management education programs or features that the applicant hopes to emulate, and places the vision and strategy of the applicant in context. The list of aspirational schools may be of any number. [Accreditation Maintenance Handbook, AACSB Blue Ribbon Committee, December 2002, pp 4-5]

The state's higher education commission had already defined the peer institutions for the university but not for the business programs. As for competitive and aspirant institutions none had been listed. The obligation to provide the three lists to AACSB was not only a requirement but was also a valuable opportunity to discover which business programs would fit into each group - an opportunity, that was a problem with no ready made solution in place. Opinions were plentiful. However, knowledge of every accredited business program in the world was in short supply - rendering opinions of limited scope. The primary goal, therefore, was to broaden the scope of comparable groups beyond what was already internally known.

A three phase decision model evolved.

1. Collect and analyze quantitative data from AACSB knowledge services

2. Develop a short list of possible programs for inclusion by interactively filtering and ranking quantitative data on various data elements to intuitively seek similar programs

3. Develop a final list using qualitative data to keep or eliminate schools from the short list.

\subsection{Collect and Analyze}

AACSB knowledge services provided very useful data at www.aacsb.edu/knowledgeservices. Table I, on the following page, lists the data available from the AACSB-Knowledge Services web site.

\begin{tabular}{|l|}
\hline \\
$\qquad \begin{array}{c}\text { Table I } \\
\text { Business Profile Data Available from AACSB Knowledge Services } \\
\text { www.aacsb.edu/knowledgeservices }\end{array}$ \\
\hline Institution Control: \\
\hline AACSB International Accreditation: \\
\hline Other Accreditation: \\
\hline 2000 Carnegie Classification: \\
\hline Web site address: \\
\hline Number of degrees in business awarded between July 1, 2000 and June 30, 2001 \\
Bachelors degrees: \\
MBA degrees: \\
Specialized Master's degrees: \\
Doctoral degrees: \\
\hline
\end{tabular}




\begin{tabular}{|l|}
\hline Bachelors degrees in Accounting/Taxation: \\
MBA degrees in Accounting/Taxation: \\
Specialized Master's degrees in Accounting/Taxation: \\
Doctoral degrees in Accounting/Taxation: \\
\hline Faculty \\
Total number of full-time faculty: \\
Total number of full-time faculty with doctoral degrees: \\
\hline Operating Budget: \\
\hline Tuition and Fees \\
Total undergraduate tuition and required fees (Resident): \\
Total undergraduate tuition and required fees (Non-Resident): \\
Total program tuition and fees for a full-time MBA student (Resident): \\
Total program tuition and fees for a full-time MBA student (Non-Resident): \\
\hline Programs in Business and Management \\
BACHELORS (Each major listed) \\
MBA (Each major/specialization listed) \\
SPECIALIZED MASTER'S (each specialization listed) \\
DOCTORAL
\end{tabular}

While AACSB provides a method for searching their database of profiles, it is tedious to cut and paste each profile in order to compare multiple profiles. A short Visual Basic macro was developed to automatically query the AACSB profile database and then cleanup and organize the results into a Microsoft Excel spreadsheet.

Once the spreadsheet was in place several additional statistics were calculated for the dataset. In an attempt to 'common size' the profiles, the following six additional statistics were developed for each institution:

1. Operating Budget per Graduate

2. Operating Budget per Full-Time Faculty Member

3. $\quad$ Operating Budget per Full-Time Faculty Member with a Terminal Degree

4. Number of Graduates per Full-Time Faculty Member

5. $\quad$ Number of Graduates per Full-Time Faculty Member with a Terminal Degree

6. Percent of Full-Time Faculty with Terminal Degrees

\subsection{Develop a Short List Using Quantitative Data}

The spreadsheet was projected on a screen in a meeting room to facilitate the reduction of the full list of AACSB accredited institutions to a short list for more in-depth study. This interactive approach provided for the data to be inspected from two perspectives.

One perspective was to look at institutions sorted into the same neighborhood when the data were sorted on various statistics - Percent of Full-Time Faculty with Terminal Degrees, for example. When looking at data from this perspective - sorting on a statistics and looking for institutions in the approximately same sort location-it became clear that each single statistic resulted in a completely different set of neighboring institutions. Attempts to find a match using a profile of multiple statistics was also unsuccessful. Clearly, this perspective did not provide a complete solution-more analyses were needed. However, this discovery approach did yield several potential candidates in that some institutions were similar on one statistics while other institutions matched up well on other statistics. The result was a list of institutions for possible inclusion-some that show similarity on financial elements while others had similar majors or enrollments.

The other perspective taken when examining the spreadsheet was to start with a particular known institution and then look for statistical similarities. Considering that the process actually started with several known institutions informally on the list, this approach allowed the initial assumptions concerning these institutions to be 
tested against the gathered statistics. The result was that some were eliminated while others were added.

At this stage a short of list of twenty candidate institutions was created. Candidates for the Competitive Comparable Group were initially set at the start of the process and remained unchanged throughout the process. The twenty candidate institutions therefore, constituted the area of primary interest; the Comparable Peers and Aspirant Groups.

\subsection{Develop a Final List Using Qualitative Data}

Once the quantitative factors had been exhausted in determining the short list of potential institutions, qualitative factors were then examined. The short list was divided up and individuals were assigned the task of finding out as much about the institution as reasonably possible. Institutional web sites were explored as well as phone calls and discussions with 'informed sources'. The intent was to develop a feel for each institution. After each institution had been researched, a decision was made that incorporated all that had been learned during the process. In most cases the qualitative information was the main factor for including the institution. However, in several instances the institution would not have been on the list except for the quantitative analysis.

\subsection{Results}

A list of candidate institutions for each of the three comparable groups was determined in a purposeful way using both quantitative and qualitative data. Whether the candidates prove to have been 'correctly' selected, in that the accreditation maintenance process functions any better, smoother, etc., may never be determined - or even determinable.

\subsection{Conclusions, Limitations, And Recommendations}

The role of the two types of data were clearly complementary in that the quantitative data was very useful as both a screening tool and as a discovery tool while the qualitative data provided an informed basis for establishing the final list.

The single major limitation lies in the non-standard data available from AACSB. All of the data in the AACSB Institution Profiles were self reported by the institutions. Some institutions did not follow the directions as accurately as others. Doubling counting of some graduates and different count of faculty were discovered. For example some institutions reported the same graduates under more than one heading. Some reported Full-Time Equivalent faculty numbers while others reported actually head counts. The most problematic area, however, was the Operating Budget item. Each budget is different in how it is reported and what is included, leaving much doubt in how to interpret the figures. Some institutions included faculty salaries in their operating budgets, while some did not. Some institutions were not charged for computing services (and therefore had no budgeted amount), while others were charged.

If AACSB intends the profile data to be useful in the selection of comparable groups, or any other purpose, then they must be concerned with the reliability and accuracy of the data by establishing clear and implementable standards. For example, rather than ask for the amount of the Operating Budget, ask for actual or estimates of the components of a typical budget. Should these discrepancies be successfully addressed, the usefulness of the profile data provided by AACSB would be greatly enhanced. 